\title{
Glutathione Peroxidase 7 Utilizes Hydrogen Peroxide Generated by Ero1 $\alpha$ to Promote Oxidative Protein Folding
}

\author{
Lei Wang, Lihui Zhang, ${ }^{1,2}$ Yingbo Niu, ${ }^{1,2}$ Roberto Sitia, ${ }^{3}$ and Chih-chen Wang ${ }^{1}$
}

\begin{abstract}
Aims: Ero1 flavoproteins catalyze oxidative folding in the endoplasmic reticulum (ER), consuming oxygen and generating hydrogen peroxide $\left(\mathrm{H}_{2} \mathrm{O}_{2}\right)$. The ER-localized glutathione peroxidase 7 (GPx7) shows protein disulfide isomerase (PDI)-dependent peroxidase activity in vitro. Our work aims at identifying the physiological role of GPx7 in the Ero1 $\alpha /$ PDI oxidative folding pathway and at dissecting the reaction mechanisms of GPx7. Results: Our data show that GPx7 can utilize Ero1 $\alpha$-produced $\mathrm{H}_{2} \mathrm{O}_{2}$ to accelerate oxidative folding of substrates both in vitro and in vivo. $\mathrm{H}_{2} \mathrm{O}_{2}$ oxidizes Cys57 of GPx7 to sulfenic acid, which can be resolved by Cys86 to form an intramolecular disulfide bond. Both the disulfide form and sulfenic acid form of GPx7 can oxidize PDI for catalyzing oxidative folding. GPx7 prefers to interact with the $a$ domain of PDI, and intramolecular cooperation between the two redox-active sites of PDI increases the activity of the Ero1 $\alpha /$ GPx7/PDI triad. Innovation: Our in vitro and in vivo evidence provides mechanistic insights into how cells consume potentially harmful $\mathrm{H}_{2} \mathrm{O}_{2}$ while optimizing oxidative protein folding via the Ero1 $\alpha /$ GPx7/PDI triad. Cys57 can promote PDI oxidation in two ways, and Cys86 emerges as a novel noncanonical resolving cysteine. Conclusion: GPx7 promotes oxidative protein folding, directly utilizing Ero $1 \alpha$-generated $\mathrm{H}_{2} \mathrm{O}_{2}$ in the early secretory compartment. Thus, the Ero $1 \alpha /$ GPx7/PDI triad generates two disulfide bonds and two $\mathrm{H}_{2} \mathrm{O}$ molecules at the expense of a single $\mathrm{O}_{2}$ molecule. Antioxid. Redox Signal. 20, 545-556.
\end{abstract}

\section{Introduction}

$\mathrm{O}$ XIDATIVE FOLDING is vital for the structure and function of most secretory and membrane proteins. In the endoplasmic reticulum (ER), disulfide bond formation is catalyzed by members of the protein disulfide isomerase (PDI) family, which typically possess CXXC active sites that are used in interchange reactions (12). Ero1 flavoproteins re-oxidize PDI and enable continuous transfer of disulfides to substrate proteins $(2,26)$. They do so using $\mathrm{O}_{2}$ as an electron acceptor and producing equimolar hydrogen peroxide $\left(\mathrm{H}_{2} \mathrm{O}_{2}\right)$ for each disulfide formed $(11,34)$. Particularly in professional secretory cells, this pathway could cause oxidative stress. How do cells deal with excess $\mathrm{H}_{2} \mathrm{O}_{2}$ in the ER? First, yeast and mammalian Ero1 proteins are elegantly regulated by feedback mechanisms, which limit reactive oxygen species production through futile cycling $(1,3,13,27,35)$. Second, $\mathrm{H}_{2} \mathrm{O}_{2}$ could introduce disulfides into folding substrates $(17,20)$, either directly or through specialized enzymes. Among the latter, peroxiredoxin $4(\operatorname{Prx} 4)$ can catalyze de novo disulfide formation at the expense of $\mathrm{H}_{2} \mathrm{O}_{2}(28,39)$. However, Prx4 can be

\section{Innovation}

To catalyze oxidative folding, Ero1-flavoproteins yield hydrogen peroxide $\left(\mathrm{H}_{2} \mathrm{O}_{2}\right)$ in stoichiometric amounts to the disulfides formed. We show that glutathione peroxidase 7 (GPx7) can utilize Ero1 $\alpha$-produced $\mathrm{H}_{2} \mathrm{O}_{2}$ in vitro and in vivo to oxidize protein disulfide isomerase (PDI) and accelerate oxidative folding. The peroxidase activity of GPx7 reveals novel mechanistic features of the catalytic and resolving cysteines. The Ero1 $\alpha / \mathrm{GPx} 7 / \mathrm{PDI}$ triad couples $\mathrm{H}_{2} \mathrm{O}_{2}$ elimination and disulfide generation to ensure efficient and safe oxidative protein folding.

\footnotetext{
${ }^{1}$ National Laboratory of Biomacromolecules, Institute of Biophysics, Chinese Academy of Sciences, Beijing, China.

${ }^{2}$ University of Chinese Academy of Sciences, Beijing, China.

${ }^{3}$ Division of Genetics and Cell Biology, Università Vita-Salute San Raffaele Scientific Institute, Milan, Italy.
} 
over-oxidized and inactivated by $\mathrm{H}_{2} \mathrm{O}_{2}$ (36), and Prx4 knockout mice have only a minor phenotype (14), implying the existence of other $\mathrm{H}_{2} \mathrm{O}_{2}$ scavengers in the secretory compartment. Recently, two ER-located glutathione peroxidases (GPx7 and GPx8) were reported to catalyze protein refolding in the presence of PDI and $\mathrm{H}_{2} \mathrm{O}_{2}$ in vitro, with GPx7 being more efficient (22). Loss of GPx7 resulted in systemic oxidative stress damage, increased carcinogenesis, and shortened life span in mice (37). However, the cell-biological evidence for the role of GPx7 / 8 in disulfide formation is still lacking. So far, the effect of activities of Prx 4 and GPx7/8 on oxidative folding was analyzed using exogenous or artificially generated $\mathrm{H}_{2} \mathrm{O}_{2}(22,39)$. We investigated whether GPx7 can use Ero1-produced $\mathrm{H}_{2} \mathrm{O}_{2}$ in situ for catalyzing disulfide formation. In this article, we focused on GPx7 for its higher in vitro activity compared with GPx8 (22).

GPx7 lacks the loop which determines glutathione (GSH) specificity and oxidizes PDI more efficiently than GSH, implying that GPx7 belongs to the family of thioredoxin GPx-like peroxidases (TGPx) $(22,29)$. In GPx7, the first cysteine residue Cys57 was supposed to be the peroxidatic cysteine $\left(C_{P}\right)$, as it is located in the -NVASxC(U)G- reactive (seleno)cysteinecontaining motif. The second cysteine residue Cys86 is located in the -FPCNQF- motif that is highly conserved among all GPx homologues, but its function remains to be clarified. Intriguingly, a canonical resolving cysteine $\left(C_{R}\right)$ in a 'Cys block' region, essential for completing the catalytic cycle of reduction by thioredoxin in typical two-cysteine TGPx, is missing in GPx7 (7, 29). Therefore, GPx7 was defined as an unusual cysteine-based TGPx, and the reaction mechanisms for GPx7 peroxidase activity were, hence, the other main aim of this study.

Our mutagenesis experiments show that Cys57 of GPx7 is oxidized by $\mathrm{H}_{2} \mathrm{O}_{2}$ to sulfenic acid, while Cys86 acts as a noncanonical $C_{R}$, resolving the sulfenylated Cys57 into an intramolecular disulfide bond. Both the disulfide and sulfenic acid forms of GPx7 can oxidize PDI. We demonstrate, moreover, that GPx7 can utilize Ero1 $\alpha$-produced $\mathrm{H}_{2} \mathrm{O}_{2}$ to accelerate oxidative folding not only in vitro but also in vivo. In this way, GPx7 allows cells to exploit the potentially harmful peroxides produced by Ero1 to improve oxidative folding, with water being released rather than any reactive oxygen species. Thus, the Ero $1 \alpha /$ GPx7/PDI triad represents an efficient and safe oxidative folding system.

\section{Results \\ GPX7 accelerates oxidative protein folding in Ero1 1/PDI system in vitro}

We previously reported that human Ero1 proteins consume one molecule of $\mathrm{O}_{2}$ to produce one disulfide in reduced thioredoxin and equimolar $\mathrm{H}_{2} \mathrm{O}_{2}(34,35)$. Here, we show that GPx7 harbors TGPx activity and can use Ero1 $\alpha$-derived $\mathrm{H}_{2} \mathrm{O}_{2}$ to promote the oxidation of thioredoxin. In this system, one $\mathrm{O}_{2}$ was consumed to produce two disulfides in thioredoxin with no $\mathrm{H}_{2} \mathrm{O}_{2}$ detected (Supplementary Fig. S1; Supplementary Data are available online at www.liebertpub.com/ars). Then, we used a physiological substrate, RNase A, instead of the artificial substrate thioredoxin to further dissect the processes of oxidative folding. On addition of exogenous $\mathrm{H}_{2} \mathrm{O}_{2}, \mathrm{GP} 7$ very efficiently co-operated with PDI to catalyze RNase A reoxidation (Fig. 1A). Next, we examined whether GPx7 could directly use Erol $\alpha$-generated $\mathrm{H}_{2} \mathrm{O}_{2}$ in RNase A re-oxidation by monitoring oxygen consumption. Oxidation of $40 \mu \mathrm{M}$ denatured and reduced RNase A (containing $160 \mu \mathrm{M}$ disulfides) by Ero1 $\alpha$ and PDI generated $\sim 16 \mu M \mathrm{H}_{2} \mathrm{O}_{2}$ (Fig. 1B), suggesting that some of the peroxides produced were used to generate disulfides directly or with the assistance of PDI in the re-oxidation of multiple disulfides-containing substrates (17). On GPx7 addition, the time needed for the completion of oxygen consumption was, at least, 10 min shorter, and $\mathrm{H}_{2} \mathrm{O}_{2}$ was no longer detected at the end of the reaction (Fig. 1B). Finally, $86 \mu \mathrm{M} \mathrm{O}_{2}$ was consumed, corresponding to two disulfides formed per molecule of $\mathrm{O}_{2}$. Importantly, in the presence of both Ero1 $\alpha$ and PDI, GPx7 was also able to promote RNase A reactivation (Fig. 1C), increasing the rate of RNase A reoxidation by $\sim 50 \%$ (Fig. 1D). When the reduced/oxidized glutathione (GSH/GSSG) redox buffer was used to supply oxidizing power with no $\mathrm{H}_{2} \mathrm{O}_{2}$ generated, GPx7 did not exert any effect and was not itself oxidized (Supplementary Fig. S2). Bovine GPx1, an enzyme that can quench $\mathrm{H}_{2} \mathrm{O}_{2}$ but cannot be reduced by PDI (22), did not promote but slightly retarded the reactivation of RNase A (Fig. 1C). Similarly, the addition of GPx7 to a mixture of Ero1 $\alpha$, PDI, and GSH resulted in accelerated GSSG production as well as increased oxygen consumption rate (Supplementary Fig. S3). The results cited earlier demonstrated that GPx7 can facilitate oxidative folding in vitro using $\mathrm{H}_{2} \mathrm{O}_{2}$ generated by Ero1 $\alpha$.

\section{GPx7 is an efficient $\mathrm{H}_{2} \mathrm{O}_{2}$ scavenger}

Of the three tryptophan residues in GPx7, Trp142 is conserved in the GPx family and located close to the $C_{P}$ active site protein data bank code (PDB: $2 \mathrm{P} 31$ ). $\mathrm{On} \mathrm{H}_{2} \mathrm{O}_{2}$ addition, a timedependent decrease of intrinsic GPx7 fluorescence was observed, mainly corresponding to quenching of Trp142 fluorescence by $\mathrm{H}_{2} \mathrm{O}_{2}$-oxidized active site. The fluorescence was then increased markedly, probably due to local conformation changes on prolonged $\mathrm{H}_{2} \mathrm{O}_{2}$ treatment (Fig. 2A). In the presence of a large excess of $\mathrm{H}_{2} \mathrm{O}_{2}$ for kinetics study, the rapid initial decrease in fluorescence was fitted to a single exponential function, representing a pseudo-first-order reaction (see inset in Fig. 2A). The rate constant for this reaction was linearly increasing in a range of $0.5-10 \mathrm{mM} \mathrm{H}_{2} \mathrm{O}_{2}$ (Fig. 2B), with the second-order rate constant of $2.6 \times 10^{3} \mathrm{M}^{-1} \cdot \mathrm{s}^{-1}$ calculated, which is comparable to that of a synuclein-fused mouse GPx7 $\left(9.5 \times 10^{3} \mathrm{M}^{-1} \cdot \mathrm{s}^{-1}\right)(6)$, and is about 30- and 300-fold greater than that for the reaction of $\mathrm{H}_{2} \mathrm{O}_{2}$ with GPx8 and PDI (22), respectively. These kinetic data indicate that GPx7 is a very efficient $\mathrm{H}_{2} \mathrm{O}_{2}$ scavenger.

\section{Cys57 is the $C_{P}$ and Cys86 is a noncanonical $C_{R}$ in $G P x 7$}

Mature GPx7 contains two cysteines, Cys57 and Cys86. To identify their roles, we replaced either one (GPx7 C57A and GPx7 C86A) or both (GPx7 DM) with alanine and examined their redox states by using 4-acetamido-4'-maleimidylstilbene-2,2'-disulfonic acid (AMS), which reacts with cysteine thiols and adds $500 \mathrm{Da}$ for each modification (Fig. 3A). In the experimental conditions utilized, AMS did not affect the mobility of GPx7 DM, confirming its specific binding to cysteine residues; the single cysteine mutants migrated comparatively slower, indicating that both Cys57 and Cys86 can be modified. Accordingly, GPx7 wild-type (WT) migrated even slower than the single cysteine mutants. After treatment with $\mathrm{H}_{2} \mathrm{O}_{2}$, GPx7 C57A still displayed the retarded mobility shift 

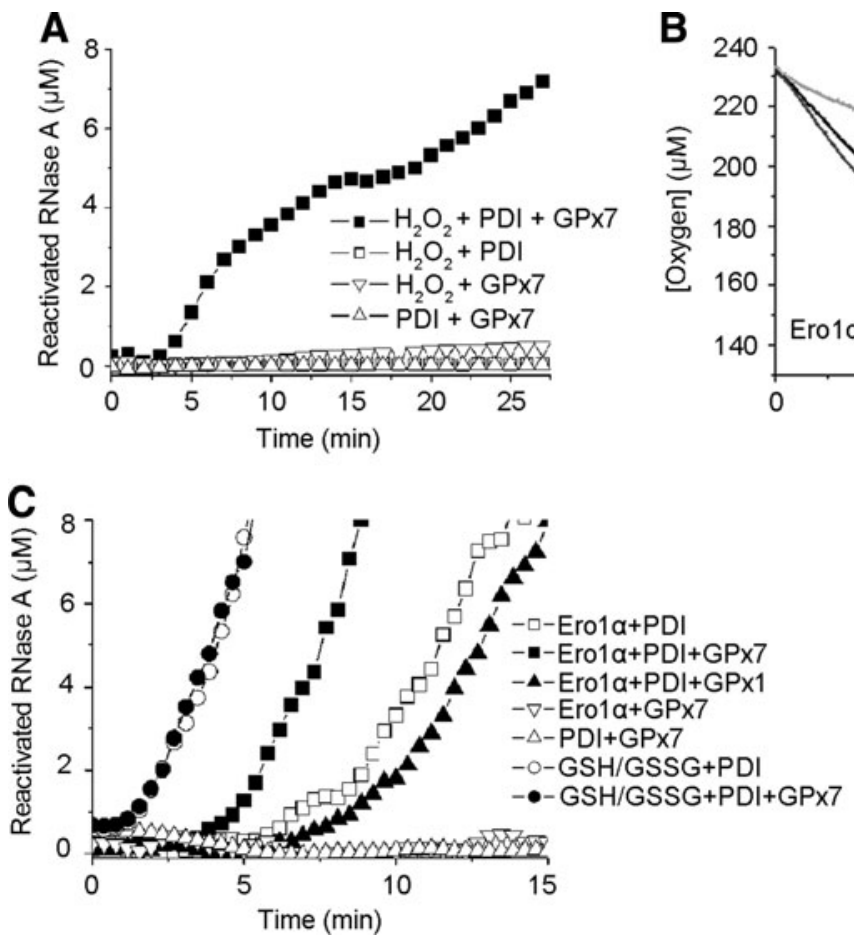
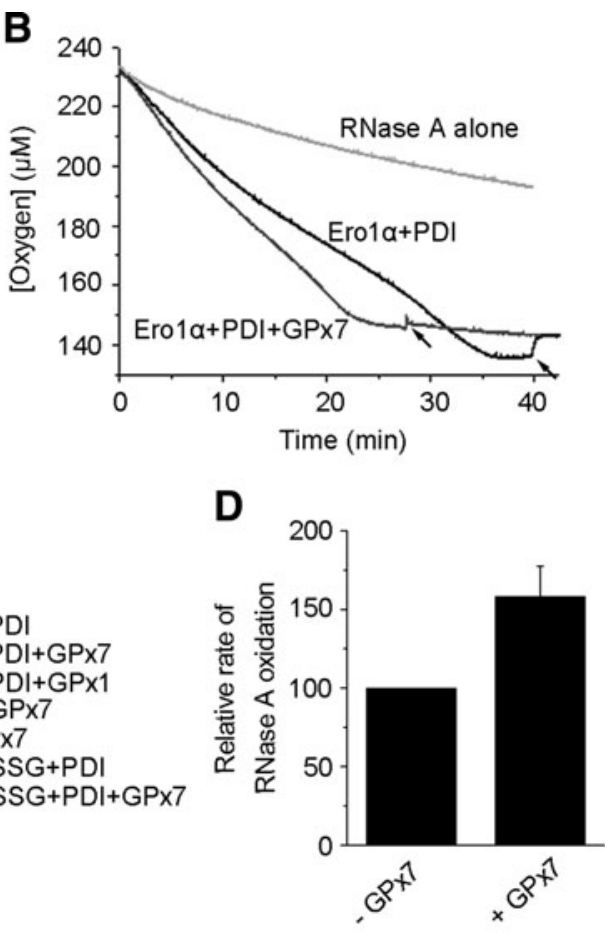

FIG. 1. Glutathione peroxidase 7 (GPx7) synergizes with Ero1 and protein disulfide isomerase (PDI) to accelerate oxidative folding in vitro. (A) RNase A $(8 \mu \mathrm{M})$ reactivation was followed by monitoring the hydrolysis of $4.5 \mathrm{mM} \mathrm{cCMP}$ in the presence of hydrogen peroxide $\left(\mathrm{H}_{2} \mathrm{O}_{2}\right)(50 \mu M)$, PDI $(3 \mu M)$, and/or GPx7 $(10 \mu M)$ as indicated. (B) Oxygen consumption was monitored as denatured, and reduced RNase A $(40 \mu M)$ was re-oxidized alone or in the presence of $3 \mu M$ Ero1 $\alpha$ and $10 \mu \mathrm{M}$ PDI, with or without $10 \mu \mathrm{M}$ GPx7. Catalase was added at the indicated time points (arrows). One out of two independent experiments with similar profiles is shown here. (C) RNase A $(8 \mu M)$ reactivation was monitored in the presence of PDI $(3 \mu M)$, Ero1 $\alpha(3 \mu M)$, GPx7 $(10 \mu M)$, GPx1 (1 unit), and/or reduced/oxidized glutathione (GSH/GSSG) redox buffer (1/ $0.2 \mathrm{mM}$ ) as indicated. (D) The relative rate of RNase A oxidation was calculated by measuring the reciprocal of the lag time before the appearance of active RNase A $(n=3)$, as described (34).

while $\mathrm{C} 86 \mathrm{~A}$ lost $\mathrm{AMS}$ reactivity, indicating that $\mathrm{Cys} 57$ but not Cys86 reacts with $\mathrm{H}_{2} \mathrm{O}_{2}$. Strikingly, $\mathrm{H}_{2} \mathrm{O}_{2}$-treated GPx7 WT migrated even faster than the C86A and DM mutants (compare lane 9 with 11 and 12), which is a characteristic of longrange intramolecular disulfide formation. The redox states of GPX7 and its mutants were further confirmed by methoxy polyethylene glycol maleimide alkylation assays, which also resulted in gel-shift retardation (Supplementary Fig. S4).

Next, we used the sulfenic acid-specific reagent, dimedonebased probe 3-(2,4-dioxocyclohexyl) propyl with a biotin tag (DCP-Bio1) (18), to characterize the reaction products of GPx7 and $\mathrm{H}_{2} \mathrm{O}_{2}$. Consistent with the notion that Cys57 can be sulfenylated by $\mathrm{H}_{2} \mathrm{O}_{2}$ and acts as the $\mathrm{C}_{\mathrm{P}}, \mathrm{GPx} 7 \mathrm{C} 86 \mathrm{~A}$ but not
C57A was detected by horseradish peroxidise-labeled streptavidin after treating with $\mathrm{H}_{2} \mathrm{O}_{2}$ and DCP-Bio1 (Fig. 3B). GPx7 WT was not modified, suggesting fast formation of an intramolecular disulfide between the sulfenylated Cys57 and Cys86, which is consistent with the pronounced mobility shift observed in Figure 3A. Thus, Cys86 plays the resolving function but is a noncanonical $C_{R}$.

\section{Both the disulfide form and sulfenic acid form of GPx7 are active to oxidize PDI}

GPx7 is an efficient PDI peroxidase with extremely weak activity toward GSH (22). To investigate the underlying
FIG. 2. Kinetics of GPx7 oxidation by $\mathrm{H}_{2} \mathrm{O}_{2}$. (A) Stopped-flow trace of time-dependent changes in the intrinsic fluorescence of $10 \mu \mathrm{M}$

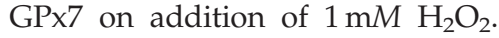
The initial reaction fits well to a pseudo-first-order reaction (inset). (B) Linear dependence of the pseudo-first-order rate constant for GPx7 oxidation on the concentration of $\mathrm{H}_{2} \mathrm{O}_{2}(n \geq 3)$.
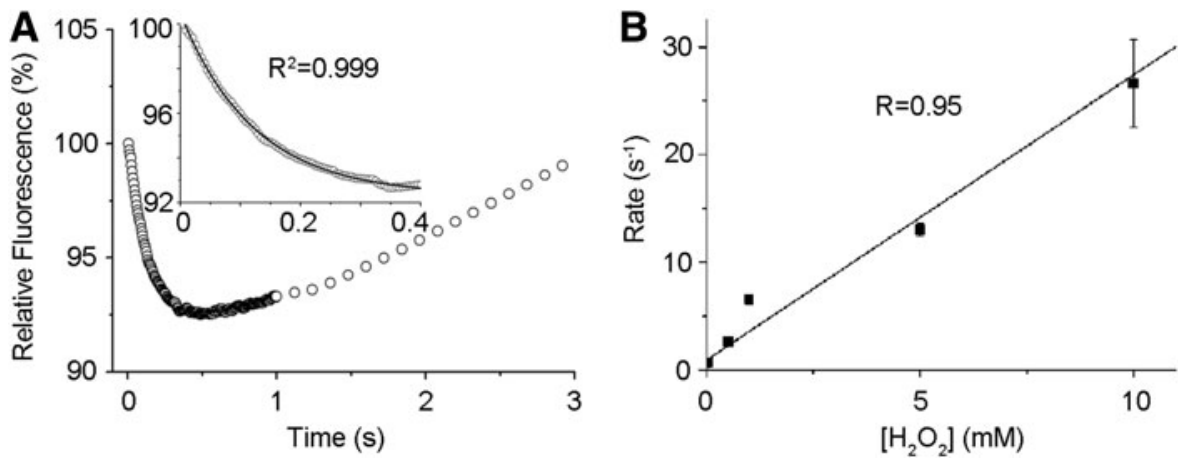


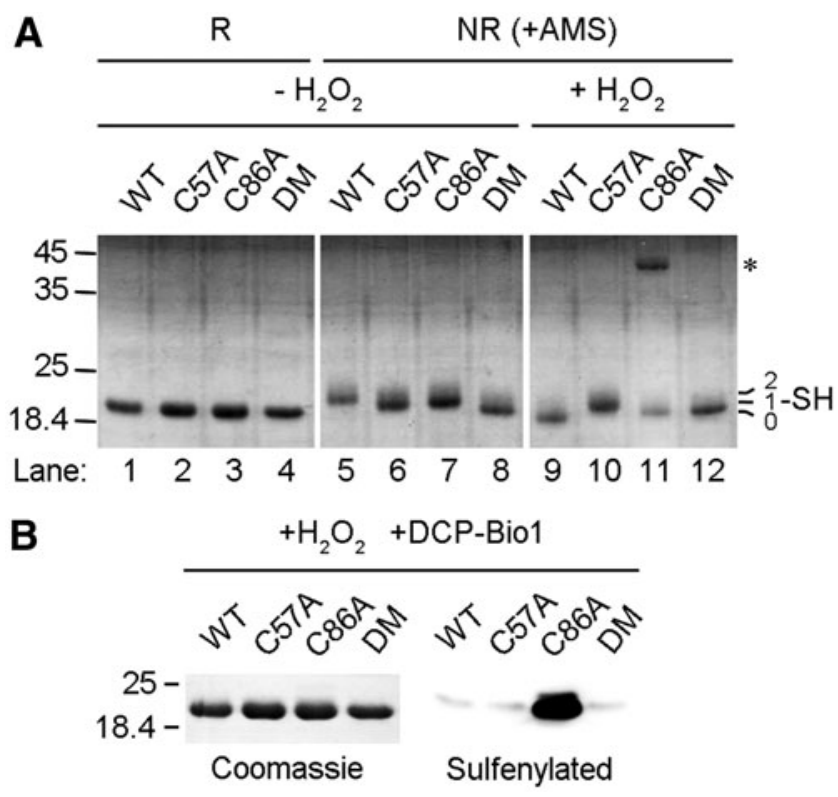

FIG. 3. Cys57 is sulfenylated by $\mathrm{H}_{2} \mathrm{O}_{2}$ and resolved by Cys86 to form an intramolecular disulfide. (A) The indicated GPx7 variants were incubated without (lanes 1-8) or with $\mathrm{H}_{2} \mathrm{O}_{2}$ (lanes 9-12), treated with (lanes 5-12) or without (lanes 1-4) the alkylating agent 4-acetamido-4'-maleimidylstilbene-2,2'disulfonic acid (AMS), and resolved by nonreducing (NR, lanes 5-12) or reducing ( $R$, lanes 1-4) sodium dodecyl sulfate-15\% polyacrylamide gel electrophoresis (SDS-15\% PAGE). Asterisk indicates GPx7 homodimers formed on $\mathrm{H}_{2} \mathrm{O}_{2}$ treatment. The numbers of thiols modified by AMS were indicated on the right margin. One representative experiment out of three is shown. (B) The indicated GPx7 variants were incubated with $\mathrm{H}_{2} \mathrm{O}_{2}$ and a biotin-tagged probe (DCP-bio1) specific to sulfenic acid, resolved by SDS-15\% PAGE, and analyzed by Coomassie staining (left panel) to monitor the loaded sample and by Western blots (WB) (right panel) to detect the sulfenylated GPx7.

reaction mechanisms, we determined the enzymatic activities of GPx7 mutants. GPx7 C86A was as active as WT; in contrast, both C57A and DM were inactive (Fig. 4A). C86A also accelerated RNase A refolding when $\mathrm{H}_{2} \mathrm{O}_{2}$ was generated by Ero1 $\alpha$, while C57A or DM showed little, if any, effect (Fig. 4B). Thus, Cys57 of GPx7 is critical for PDI peroxidase activity. AMS modification assays were then used to determine changes in the redox state of GPx7 and PDI during the reaction. A single PDI active domain was used instead of fulllength PDI in these experiments, because the redox shift is more evident in molecules of lower molecular weight. As shown in Figure 4C, the reduced PDI $a$ domain was gradually oxidized after equimolar $\mathrm{H}_{2} \mathrm{O}_{2}$ addition, and was completed after $30 \mathrm{~min}$. Conversely, the intramolecular disulfide form of GPx7 WT due to immediate oxidation by $\mathrm{H}_{2} \mathrm{O}_{2}$ gradually shifted to the reduced form. GPx7 C86A with the sulfenylated $\mathrm{C}_{\mathrm{P}}$ also oxidized PDI $a$ domain, albeit less efficiently than WT, which is probably due to the formation of less-active C86A homodimers in the absence of reducing equivalents in the system. Neither mutant lacking $C_{P}($ C57A or DM) oxidized PDI $a$ domain. Next, to identify the PDI-reacting cysteine in GPx7, we examined complex formation between GPx7 and PDI in the absence of $\mathrm{H}_{2} \mathrm{O}_{2}$. A mutant PDI (C56A) was used, because replacing the $\mathrm{C}$-terminal cysteine in the $\mathrm{CGHC}$ active site allows trapping mixed disulfides in interchange reactions (15). PDI C56A formed covalent complexes of $\sim 70 \mathrm{kDa}$ only with GPx7 C86A (Fig. 4D), indicating that Cys57 forms mixed disulfides with PDI which are resolved by Cys86. Taken together, the results cited earlier suggest that both the disulfide form and sulfenic acid form of GPx7 can directly oxidize PDI and accelerate disulfide formation in substrates, although with different kinetics.

\section{GPX7 accelerates oxidation of reduced $J$ chain in cells depending on Ero1 $\alpha$ activity}

To investigate whether GPx7 can promote oxidative protein folding in living cells, we monitored disulfide bond formation in myc-tagged Ig J chains (JcM) (21). When HeLa transfectants expressing the reporter were briefly exposed to dithiothreitol (DTT), most JcM migrated as reduced monomers with a few homodimers (Fig. 5A, lane 1). On removal of the reducing agent, oxidized species (monomers, dimers, and highmolecular-weight complexes) progressively appeared (lane 4). As previously described (21), in cells co-expressing Ero1 $\alpha$, oxidized JcM monomers were detected already at the end of the pulse (lane 5), and dimers and high-molecular-weight species formed more rapidly during the chase, confirming that Ero1 $\alpha$ functions as an efficient sulfhydryl oxidase. Co-expression of GPx7 resulted in accelerated disappearance of reduced JcM monomers, albeit to a lesser extent compared with Ero1 $\alpha$ (compare, for instance, lanes 9 and 5, or 11 and 7). Densitometric quantifications confirmed that GPx7 promotes the oxidation of reduced JcM in living cells (Fig. 5B). Intriguingly, on GPx7 overexpression, fewer JcM-containing covalent complexes accumulated and could be detected only on prolonged exposure (Supplementary Fig. S5). These JcMcontaining covalent complexes could still be detected immediately after DTT treatment when Ero1 $\alpha$ was overexpressed (Fig. 5A, lane 5), which may represent the "old" molecules that are trapped in partially DTT-resistant complexes in this nonradioactive chase (5). It might be also possible that these covalent complexes were the consequence of indiscriminate oxidation by $\mathrm{H}_{2} \mathrm{O}_{2}$, which resulted from robust Ero1 $\alpha$ oxidase activity after DTT challenge, and they were inhibited by the peroxidase activity of GPx7.

Even if expressed at comparable levels, the cysteine mutants GPx7 C57A and DM were less efficient than WT in inducing the disappearance of reduced JcM monomers (Fig. 5C). GPx7 C86A retained partial activity (Fig. 5D). These observations confirm that Cys57 plays a critical role for peroxidase activity also in vivo, and the presence of Cys86 as a $C_{R}$ is important for catalyzing disulfide formation in cells.

To provide further evidence that the effect of GPx7 on oxidative folding is dependent on Ero1 $\alpha$ activity, endogenous Ero1 $\alpha$ was knocked down by expressing Ero1 $\alpha$-targeting short hairpin RNA (shEro1 $\alpha$ ). Reduced JcM monomers in control cells disappeared faster at $30^{\circ} \mathrm{C}$ than at $20^{\circ} \mathrm{C}$ (compare lanes $1-4$ in Fig. 5E, A). On Ero1 $\alpha$ knockdown, the re-oxidation of JcM was significantly delayed (Fig. 5E, lanes 5-8), in line with the observation that the restoration of ER redox homeostasis after DTT challenge is compromised by Ero1 $\alpha$ depletion (31). Ectopic expression of GPx7 on the background of Ero1 $\alpha$ knockdown did not have a significant effect on JcM reoxidation (Fig. 5F), strongly suggesting that the acceleration effect of GPx7 on JcM re-oxidation was dependent on Ero1 $\alpha$ 
FIG. 4. Cys57 of GPx7 is required for PDI peroxidase activity. (A) GPx activity was measured after the decrease in absorbance at $340 \mathrm{~nm}$ due to reduced nicotinamide adenine dinucleotide phosphate (NADPH) consumption by glutathione reductase, in the presence of $40 \mu \mathrm{M}$ $\mathrm{H}_{2} \mathrm{O}_{2}$, $0.5 \mathrm{mM}$ GSH, and $10 \mu M$ PDI, with or without $10 \mu M \quad$ GPx7 mutants. (B) RNase A $(8 \mu M)$ reactivation was determined in the presence of $3 \mu \mathrm{M}$ Ero $1 \alpha$ and PDI with or without the indicated GPx7 mutants $(10 \mu \mathrm{M})$. (C) The change in the redox status of PDI $a$ domain after incubation with the indicated GPx7 variants and $\mathrm{H}_{2} \mathrm{O}_{2}$ was analyzed by nonreducing SDS-15\% PAGE after alkylation with AMS. The reduced (Red.) and oxidized (Ox.) forms of PDI $a$ domain are indicated. The reduced (2$\mathrm{SH})$ and intramolecular disulfide form (0-SH) in GPx7 wild type (WT) are indicated as well. One representative experiment out of two is shown. (D) GPx7 variants were incubated with PDI C56A, blocked by N-ethylmaleimide (NEM), and then resolved by reducing $(\mathrm{R})$ or non-reducing (NR) SDS-12\% PAGE. The domain architecture and CGHC active sites of PDI are schematically illustrated in the lower panel.
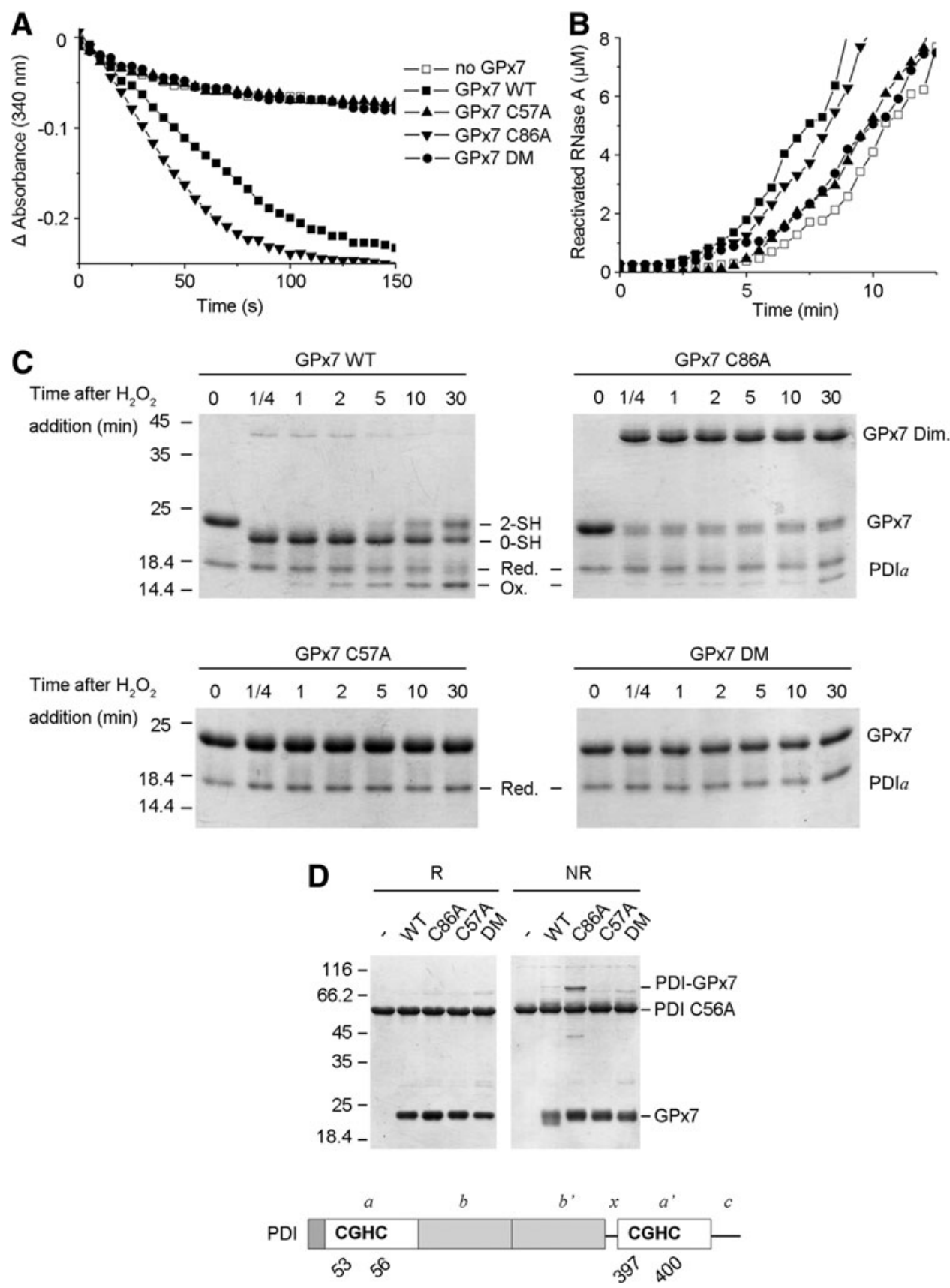

activity. The results cited earlier implied that in living cells, GPx7 can efficiently utilize Erol $\alpha$-derived $\mathrm{H}_{2} \mathrm{O}_{2}$, which should be the main source of $\mathrm{H}_{2} \mathrm{O}_{2}$ produced after reductive challenge.

\section{GPX7 and Ero1 $\alpha$ bind to PDI separately}

Having determined that GPx7 potentiates the Ero1 $\alpha /$ PDI system in vitro and in vivo, we performed glutathione S-transferase (GST)-pulldown studies to detect possible binary or ternary complexes. Approximately $4 \%$ of PDI from HeLa cell lysates specifically bound to GST-GPx7 WT or DM chimeras. Ero1 $\alpha$ was not detected in the bound fraction (Fig. 6A). Thus, PDI can bind to GPx7 through noncovalent interactions.

We once again took advantage of the PDI cysteine trapping mutants to analyze the ability of the $a$ and $a^{\prime}$ domains to covalently interact with GPx7 in HeLa cells. Clearly, as shown in Figure 6B, the covalent GPx7-PDI complexes were more abundant with PDI C56A (* in lanes 2 and 11) than with PDI C400A (** in lanes 3 and 12), and these bands faded on DTT treatment. After removal of the reducing agent, the complex between GPx7 and PDI $a$ domain re-emerged at $30 \mathrm{~min}$ (lanes 8 and 17). These mixed disulfides likely reflect intermediates in the oxidation of PDI by $\mathrm{H}_{2} \mathrm{O}_{2}$ catalyzed by GPx7 in cells. Altogether, these results indicate that GPx7 interacts preferentially with the PDI $a$ domain.

Interactions between Ero1 $\alpha$, GPx7, and PDI were further investigated by overexpressing Ero1 $\alpha$, GPx7 C86A, and PDI C56A in combinations (Fig. 6C). Ero1 $\alpha$ covalently bound to 
A
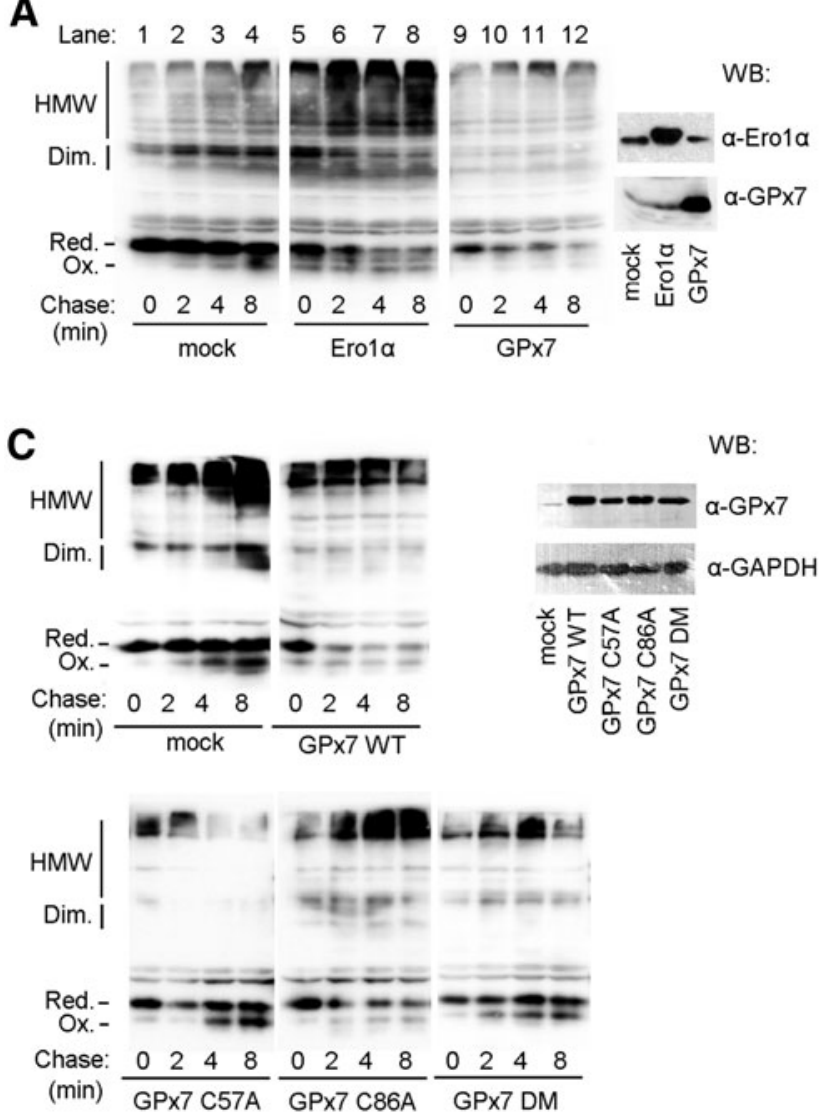

E

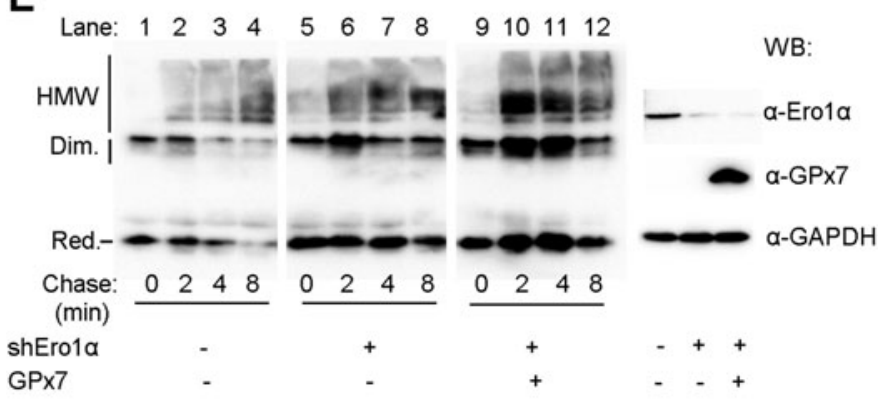

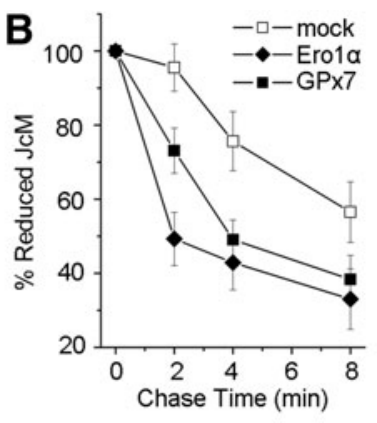
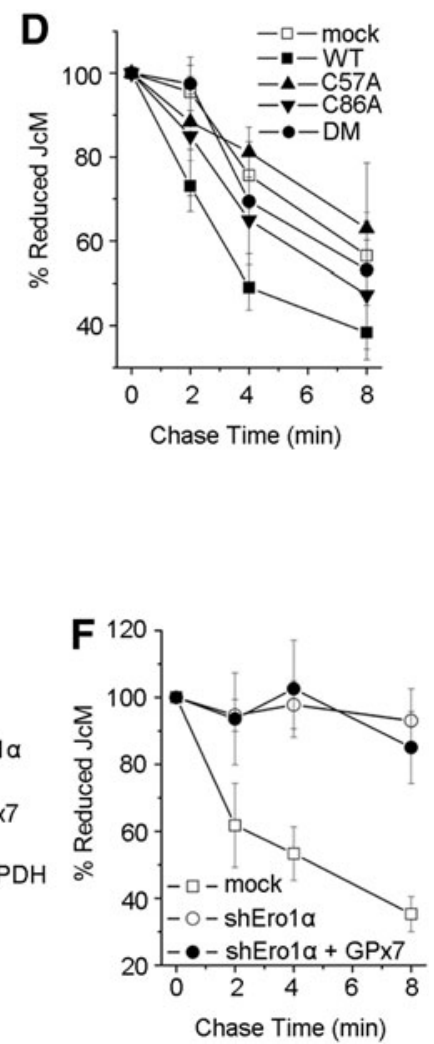

FIG. 5. GPx7 accelerates oxidative protein folding in vivo. HeLa transfectants expressing JcM alone (mock), or combined with Ero1 $\alpha$, GPx7 (A), or its cysteine mutants (C) were treated with dithiothreitol (DTT), washed, and incubated without reducing agent at $20^{\circ} \mathrm{C}$ for the indicated time. After NEM blocking, cell lysates were analyzed by nonreducing SDS-PAGE and decorated by anti-myc. The mobility of reduced JcM monomers (Red.), oxidized monomers (Ox.), homodimers, and high-molecular-weight complexes (HMW) is indicated. Each sample at $0 \mathrm{~min}$ was resolved by reducing SDS- $12 \%$ PAGE and decorated with antiEro1 $\alpha$ or anti-GPx7 antibodies. (E) JcM expressing $\mathrm{HeLa}$ cells were co-transfected with or without shEro1 $\alpha$ and GPx7 plasmid as indicated. Experiments were carried out as in (A), except that the incubation after DTT washout was at $30^{\circ} \mathrm{C}$, at which JcM oxidation in mock cells was faster than at $20^{\circ} \mathrm{C}$, and the effects of Ero1 $\alpha$ knockdown were more distinct. The disappearance of fully reduced JcM monomers in (A), (C), and (E) was quantified by densitometry and plotted as the percent remaining at each time point relative to $0 \mathrm{~min}$ in (B), (D), and (F), respectively $(n \geq 3$, mean \pm S.D.). endogenous PDI (see bands indicated by open arrowheads in lanes 4 and 9), likely via the $a^{\prime}$ domain (25), and to both $a$ and $a^{\prime}$ domains in PDI C56A mutant (see bands indicated by open and closed arrowheads in lanes 3 and 8). GPx7 C86A was linked to the $a$ domain of PDI C56A (see bands indicated by diagonal arrows in lanes 2 and 12, and also see Fig. 6B). When the three proteins were co-expressed together in cells, the binary complexes (PDI-Ero1 $\alpha$ and PDI-GPx7) were clearly visible. In contrast, bands corresponding to ternary complex were not detected (compare, for instance, lanes 10 and 8, or 15 and 12), suggesting that GPx7 and Ero1 $\alpha$ covalently bind to PDI in a sequential way rather than simultaneously.

\section{Two active sites of PDI cooperate intramolecularly in the Ero1 $\alpha / G P x 7 / P D I$ system}

In order to dissect the Ero1 $\alpha /$ GPx7/PDI system in greater detail, we measured the amount of the disulfides generated by monitoring GSH oxidation into GSSG in vitro. Consistent with the notion that PDI metabolizes $\mathrm{H}_{2} \mathrm{O}_{2}$ inefficiently (22), very few disulfides were formed in the presence of exogenous $\mathrm{H}_{2} \mathrm{O}_{2}$ only (Fig. 7A, white). The presence of GPx7 markedly accelerated disulfide bond formation catalyzed by PDI WT. In the presence of GPX7, PDIC1 and PDIC2 mutants, in which both cysteines were replaced by serines in the $a$ and $a^{\prime}$ domain active sites separately, catalyzed GSH oxidation by $\mathrm{H}_{2} \mathrm{O}_{2}$, albeit less efficiently than PDI WT. Mixing PDIC1 and PDIC2 restored the peroxidase activity for GPx7, similar with PDI WT (Fig. 7A, black). Thus, GPx7 can readily oxidize either active site of PDI with excess $\mathrm{H}_{2} \mathrm{O}_{2}$.

Next, Ero1 $\alpha$ was used to supply an oxidizing source instead of exogenous $\mathrm{H}_{2} \mathrm{O}_{2}$. In accordance with a previous finding that Ero1 $\alpha$ preferentially oxidizes the $a^{\prime}$ active site in PDI (3, 34), PDIC1 was able to generate disulfides. In contrast, a few disulfides were produced by PDIC2 (Fig. 7B, white). As expected, GPX7 was active toward PDIC1 but inactive toward 


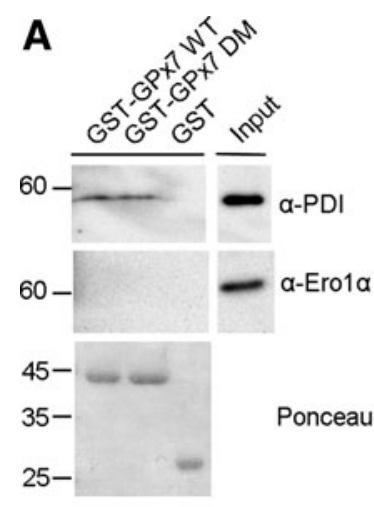

B GPX7 C86A-Myc
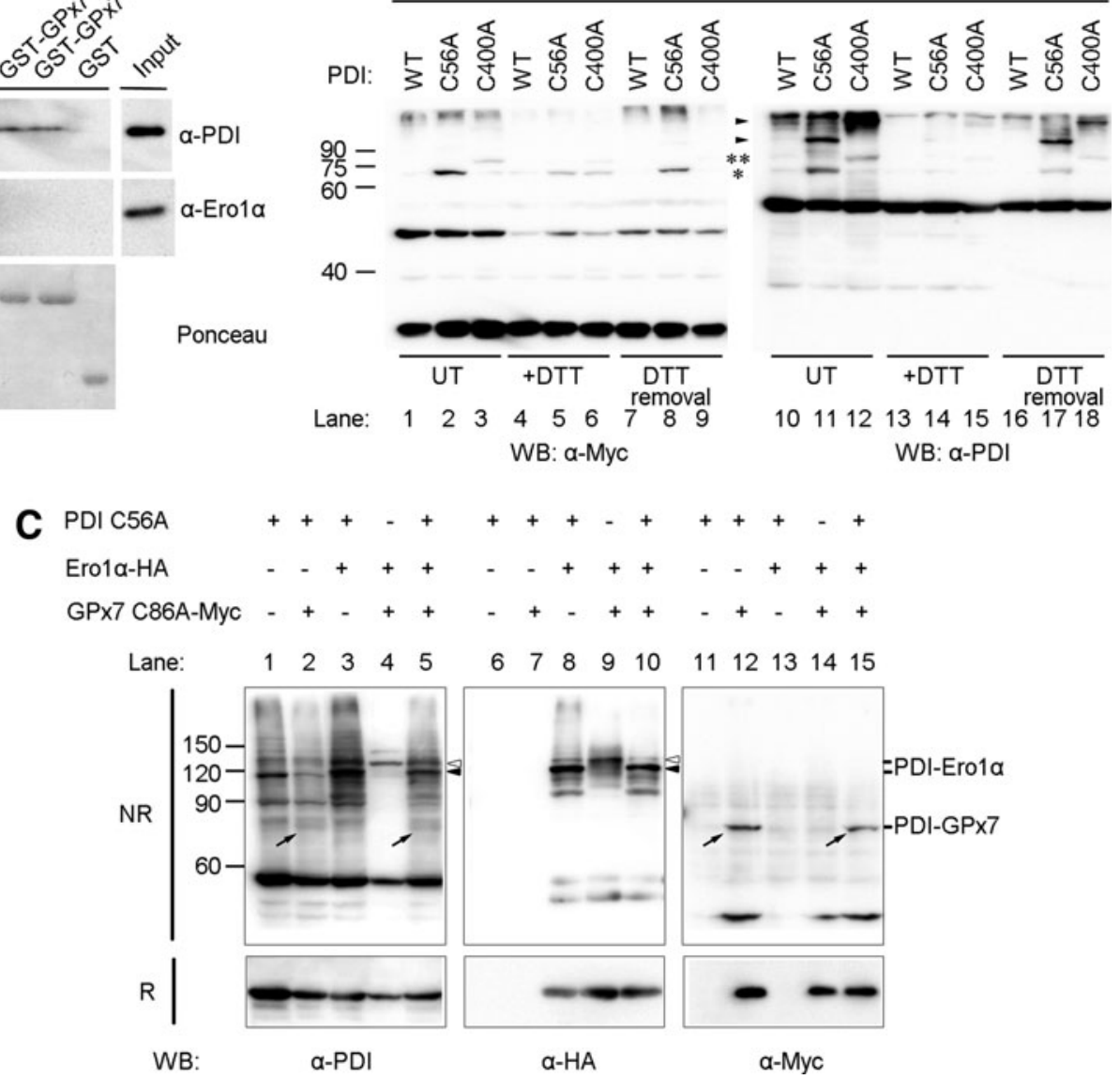

FIG. 6. Formation of covalent binary complexes by GPx7, Ero1 $\alpha$, and PDI. (A) Aliquots of glutathione S-transferase (GST)GPx7 WT, GST-GPx7 DM, or GST were incubated with HeLa cell lysates and precipitated with GSH-Sepharose. The precipitated proteins and 1/10 of the whole lysates (Input) were analyzed by WB with anti-PDI or anti-Ero1 $\alpha$. PDI, but not Ero1 $\alpha$, was detected in the precipitated fractions. Ponceau staining (lower panel) was used to visualize GST-chimeric proteins. (B) PDI WT or the two CGHA trapping mutants (C56A and C400A) were co-expressed in HeLa cells with myc-tagged GPx7 C86A. Aliquots of untreated (UT) cells or those treated with exogenous reducing agent (+DTT) were modified with NEM, resolved by SDS-12\% PAGE under nonreducing conditions, and decorated with anti-myc or anti-PDI. After DTT treatment, some cells were washed and cultured for $30 \mathrm{~min}$ in DTT-free medium (DTT removal) to follow the formation of intermolecular complexes. The single $\left(^{*}\right)$ or double asterisks $\left(^{* *}\right)$ point at adducts between Cys57 of GPx7 and the N-terminal cysteines of $a$ or $a^{\prime}$ PDI active sites, respectively. The arrowheads indicated the disulfide-linked complexes between PDI and other client proteins (e.g., Ero1s). (C) PDI C56A, HA-tagged Ero1 $\alpha$, and myc-tagged GPx7 C86A were expressed in combinations in HeLa cells. Cells were treated by NEM, and lysates were resolved under nonreducing (NR, 8\% SDS-PAGE) or reducing $(\mathrm{R}, 12 \%)$ conditions and decorated with antibodies as indicated. The open and closed arrowheads point to the mixed disulfides formed between Ero1 $\alpha$ and PDI $a^{\prime}$ and $a$ domains, respectively. The diagonal arrows indicate the complexes between GPx7 and PDI. Notice that the exposure time for the left panel is shorter than that for the right panel and (B) in order to make the abundant PDI-Ero1 $\alpha$ complexes not too strong to be distinguished; although the bands corresponding to PDIGPx7 complexes are somehow faint, they are clearly seen in the right panel and (B).

PDIC2, as Ero1 $\alpha$ does not oxidize the $a$ active site producing little $\mathrm{H}_{2} \mathrm{O}_{2}$. Nevertheless, the activity of GPx7 toward PDIC1 was lower than toward PDI WT, suggesting that the active $a$ domains contribute to the interactions with GPx7, although not involved in binding Ero1 $\alpha$. However, adding PDIC2 (with intact $a$ domain) to PDIC1 did not increase the activity in the Ero1 $\alpha /$ GPx7/PDI system (Fig. 7B, black), which is different from using exogenous $\mathrm{H}_{2} \mathrm{O}_{2}$ as the oxidizing source. The fact that PDIC1 and PDIC2 did not show any synergy for GPx7 in this system suggested that the $\mathrm{H}_{2} \mathrm{O}_{2}$ produced on the oxidation of PDI $a^{\prime}$ domain by Ero1 $\alpha$ can only be efficiently used by GPx7 to oxidize the $a$ domain of the same PDI molecule. Thus, maximal activity of the Ero1 $\alpha / \mathrm{GPx} 7 / \mathrm{PDI}$ triad requires intramolecular co-operation between the $a$ and $a^{\prime}$ sites in PDI.

\section{Discussion}

We have reconstructed an efficient, ER-based oxidative folding system composed of a sulfhydryl oxidase (Ero1 $\alpha$ ), an oxidoreductase/isomerase (PDI), and a peroxidase (GPX7). Our in vitro and in vivo assays enable the depiction of a working model for the Ero1 $\alpha /$ GPx7/PDI triad (Fig. 8A). Ero1 $\alpha$ preferentially oxidizes the $a^{\prime}$ domain of PDI, generating one molecule of $\mathrm{H}_{2} \mathrm{O}_{2}$ and a partially oxidized PDI at the 

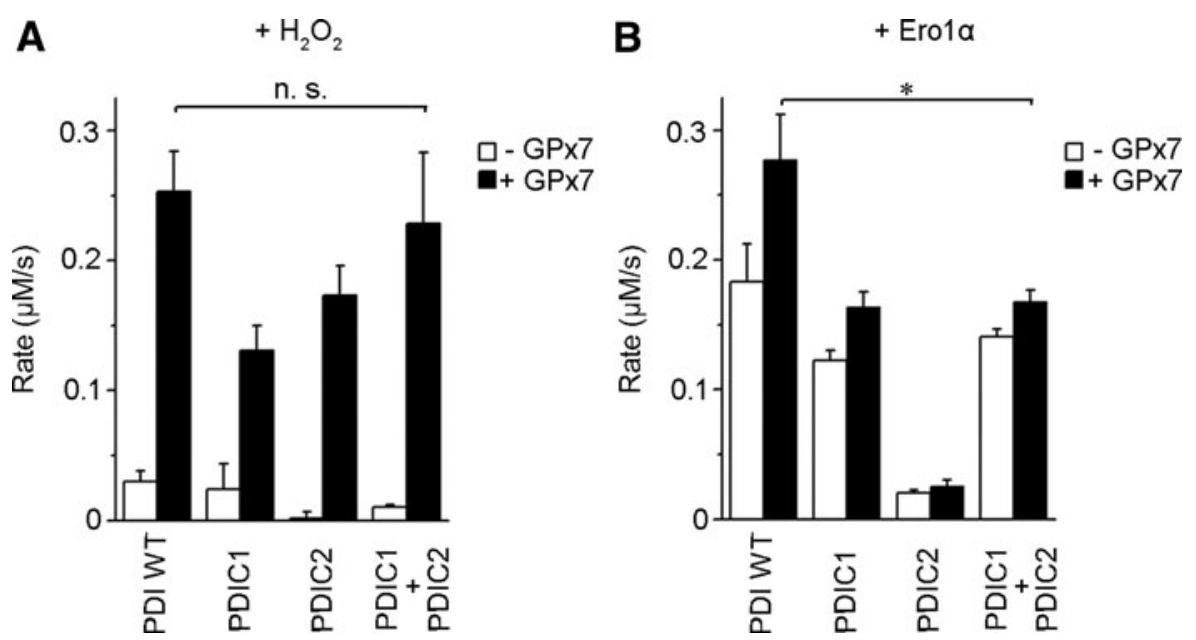

FIG. 7. Intramolecular cooperation between the two PDI active sites. (A) GPx activity was measured on NADPH oxidation in the presence of glutathione reductase with $0.5 \mathrm{mM} \mathrm{GSH}$ and $0.2 \mathrm{mM} \mathrm{H} \mathrm{O}_{2}$ as described (22), in the presence of $10 \mu M$ PDI or its active site mutants PDIC1 (SGHS in the $a$ domain) and PDIC2 (SGHS in the $a^{\prime}$ domain), with or without $10 \mu M$ GPx7, as indicated. (B) GPx activity was measured with $2 \mu M$ Ero1 $\alpha$ to generate $\mathrm{H}_{2} \mathrm{O}_{2}$, in the presence of $10 \mu M$ PDI and $5 \mathrm{mM} \mathrm{GSH}$, as sufficient GSH is required for reduction of the regulatory disulfides during Ero1 $\alpha$ activation (unpublished data). The rates of NADPH consumption were calculated, which correspond to the rates of disulfide formation $(n \geq 3$, mean \pm S.D.). Asterisk indicates statistical significance $(p<0.05)$; n.s., not significant.

expense of one $\mathrm{O}_{2}$ molecule (Step I). GPx7 uses the $\mathrm{H}_{2} \mathrm{O}_{2}$ generated by Ero1 $\alpha$ in situ for oxidizing the $a$ domain of the same PDI molecule, preventing diffusion of this reactive oxygen species (Step II). Fully oxidized PDI transfers disulfides into substrates for oxidative folding. Via this mechanism, a single $\mathrm{O}_{2}$ molecule can generate two disulfide bonds and two harmless $\mathrm{H}_{2} \mathrm{O}$ molecules. A bimolecular fluorescence complementation experiment in cells suggested a possible physical association between Ero1 $\alpha$ and GPx7 (22), and our model suggests that Ero1 $\alpha$ and GPx7 preferentially bind to the $a^{\prime}$ and $a$ domain of PDI separately in a sequential way, and maybe transiently close to each other. There are other potential
A
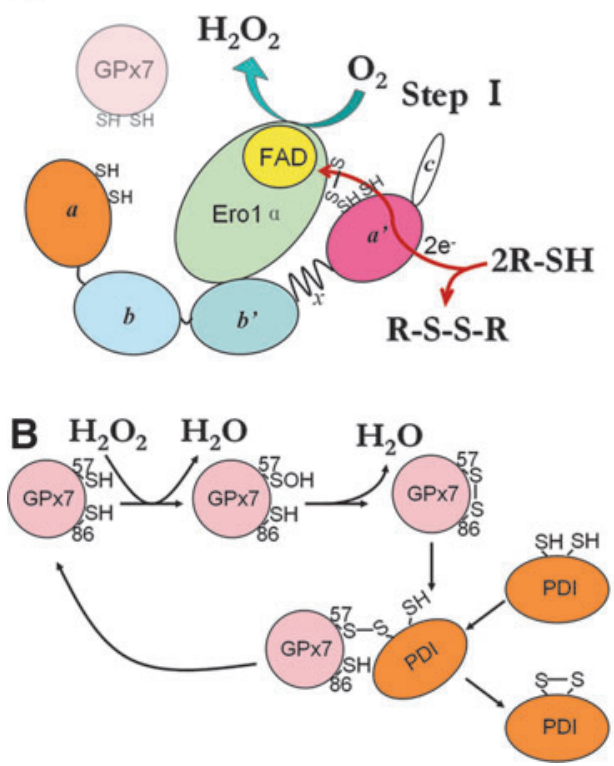
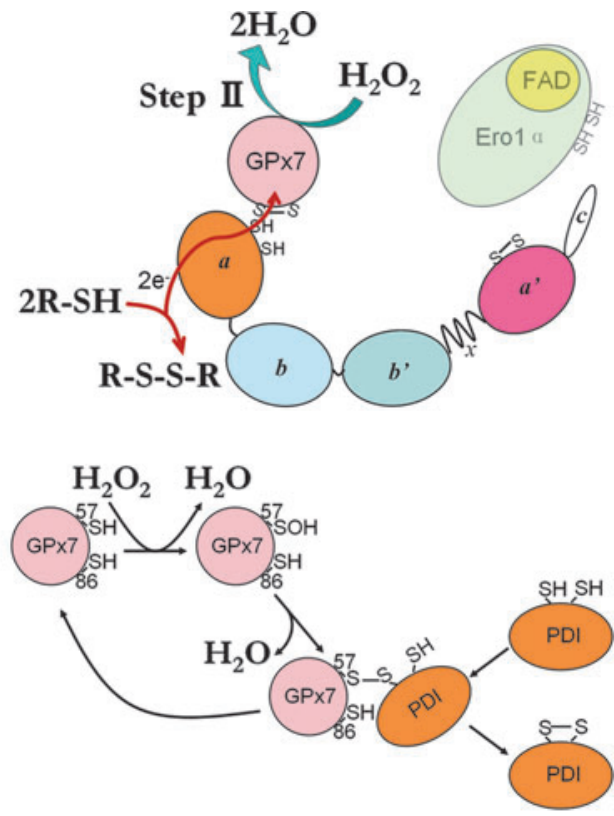

FIG. 8. Schematic model of the Ero1 $\alpha /$ GPx7/PDI triad in oxidative protein folding. (A) The $a^{\prime}$ domain of PDI is oxidized by Ero1 $\alpha$, generating one molecule of $\mathrm{H}_{2} \mathrm{O}_{2}$ (left panel), which is subsequently caught by vicinal GPx7 to oxidize the $a$ domain of PDI (right panel). Oxidized PDI can then transfer disulfide bonds to substrates. In this way, a single $\mathrm{O}_{2}$ molecule generates two disulfide bonds and two $\mathrm{H}_{2} \mathrm{O}$ molecules. The detailed mechanism for peroxidase activity of GPx7 is shown in (B): $\mathrm{H}_{2} \mathrm{O}_{2}$ oxidizes Cys57 of GPx7 to a sulfenic acid, releasing one molecule of water. The sulfenylated Cys57 is then attacked by Cys86 (left panel) or the N-terminal cysteine in the CGHC active site of PDI (right panel) to form an intra- or inter-molecular disulfide, releasing the second molecule of water. Through further thiol-disulfide exchange, PDI is oxidized and GPx7 is reduced. Only one active domain of PDI is shown here for simplicity. To see this illustration in color, the reader is referred to the web version of this article at www.liebertpub.com/ars 
pathways for productive utilization of $\mathrm{H}_{2} \mathrm{O}_{2}$ in mammalian ER. GPx8, also localizing in close proximity to Ero1 $\alpha$ in cells, shows weaker PDI-peroxidase activity in vitro (22) and has one order of magnitude lower reactivity with $\mathrm{H}_{2} \mathrm{O}_{2}$, compared with GPx7 (Fig. 2). Interestingly, GPx8 can prevent accumulation of Ero1 $\alpha$-derived $\mathrm{H}_{2} \mathrm{O}_{2}$ and ER stress in living cells (Ramming and Appenzeller-Herzog, personal communication), but whether GPx8 could promote oxidative folding by using Erol $\alpha$-derived $\mathrm{H}_{2} \mathrm{O}_{2}$ in situ is still an open question. The two-cysteine Prx4 was reported to catalyze disulfide formation in vitro and in vivo $(28,39)$. However, Prx 4 can be inactivated by $\mathrm{H}_{2} \mathrm{O}_{2}$, and no enzymes that are capable of reducing over-oxidized Prxs (such as sulfiredoxin) have been found so far in the ER (36). Different from Prx4, GPx7 is hardly inactivated at a sub-millimolar concentration of $\mathrm{H}_{2} \mathrm{O}_{2}$ (unpublished data), implying that GPx7 is either resistant to overoxidation or protected by PDI. A certain degree of redundancy of peroxidase activities in the early secretory compartment may be important to optimize oxidative folding while limiting the risks of oxidative stress.

Different from canonical cysteine-based TGPx in invertebrates and plants, GPx7 lacks the corresponding $C_{R}$ known to confer preferential reducibility by thioredoxin (7). Here, we demonstrate the function of Cys86 to resolve the Cys57 sulfenic acid to form an intramolecular disulfide for PDI oxidation (Fig. 8B, left panel). Moreover, the presence of Cys86 also prevents the formation of the less-active GPx7 homodimers bridged by two $C_{P}$ (Fig. $4 C$ ). Therefore, Cys86 emerges as a novel noncanonical $C_{R}$. This cysteine residue is conserved in a similar position among almost all GPx members; however, whether the analogues of Cys86 in other TGPx without canonical $\mathrm{C}_{\mathrm{R}}$ (e.g., human GPx5) can also play resolving roles is currently unclear. Since the sulfur atoms of the two cysteine residues in reduced GPx7 are located $\sim 11 \AA$ away protein data bank code (PDB: 2P31), it is expected that the formation of the intramolecular disulfide should result in significant conformational changes. The observation that GPx7 C86A can also oxidize PDI, suggests an alternative pathway (Fig. 8B, right panel), in which the sulfenylated $\mathrm{C}_{\mathrm{P}}$ directly oxidizes PDI via an intermolecular disulfide. This is similar to the way in which yeast TGPx Orp1 oxidizes the transcription factor Yap1 (9). Therefore, PDI can react with Cys57 of GPx7, either in the sulfenylated form or in the disulfide form. On the other hand, Cys86 was recently reported to be critical for the formation of GPx7-GRP78 covalent complexes in vitro, at an extremely high concentration of $\mathrm{H}_{2} \mathrm{O}_{2}$ (37). In this case, the possibility that Cys57 was inactivated to $-\mathrm{SO}_{2} / \mathrm{SO}_{3}$ forms by $\mathrm{H}_{2} \mathrm{O}_{2}$ cannot be ruled out. Therefore, whether GPx7 could adopt additional ways to interact with its partner proteins still needs further investigation. An interesting feature of GPx7 is that it passes the oxidizing equivalents to PDI rather than directly to GSH (22), and the rate constant for the reduction of GPx7 by PDI is 270 -fold faster than that by GSH (6). In this regard, we did not observe any change of oxidized to total glutathione ratio in GPx7-transfected HeLa cells at a steady state (Supplementary Fig. S6). Similarly, Ero1 and Prx4 proteins prefer PDI compared with GSH as substrates (8). In addition, the ER thioldisulfide homoeostasis is not changed on ectopic expression of WT Ero1 $\alpha$, unless the deregulated hyperactive Ero1 $\alpha$ was introduced (1). These results imply that the ER redox homeostasis is tightly controlled, and PDI plays a pivotal role in oxidative folding, preventing futile consumption of GSH and ensuring correct disulfide formation. Moreover, since the chaperone activity and the overall structure of human PDI are redox regulated $(32,33)$, the oxidation of PDI by GPx7 could result in conformational changes and elevated chaperone activities in cells, which could be another oxidative stressinduced cellular protective pathway.

The observations that GPx7 is down-regulated in breast cancer cells (30) and esophageal adenocarcinoma (23) suggest a tumor suppressor function of GPx7, possibly by preventing cells from high levels of reactive oxygen species and oxidative DNA damage. In accordance with this, GPx7 knockout mice suffered from systemic oxidative stress damage, increased carcinogenesis, and shortened life span (37). Recently, it was revealed that Ero1 $\alpha$ is highly expressed in esophageal and gastric cancer cells (4), further emphasizing the importance of ER redox regulation in the pathophysiology of the gastrointestinal tract. Considering our observations that GPX7 can directly react with Ero1 $\alpha$-derived $\mathrm{H}_{2} \mathrm{O}_{2}$, it will be very interesting to investigate whether there exists any coincidence and/or correlation between the decrease of GPx7 and increase of Ero $1 \alpha$ in the development of these cancers. In view of the key roles of $\mathrm{H}_{2} \mathrm{O}_{2}$ in cell signaling and pathophysiology, further work is also needed to characterize the network of peroxide in terms of sources (38), scavengers (16), and regulation in the secretory compartment. Emerging evidence on the relationship between disulfide formation and diseases associated with redox imbalance also highlight the enzyme molecules involved in ER redox homeostasis as potential targets for both biomarker and drug development in these diseases.

\section{Materials and Methods}

\section{Plasmids and protein purification}

The pKEHS780 plasmid encoding the mature human GPx7 (Q20-L187) without signal sequence was a kind gift from L. Ruddock. BL21 (DE3) cells (Novagen) expressing GPx7 were grown in Luria-Bertani medium containing $100 \mu \mathrm{g} / \mathrm{ml}$ of ampicillin at $37^{\circ} \mathrm{C}$ for $4 \mathrm{~h}$, and shaken for $20 \mathrm{~h}$ at $25^{\circ} \mathrm{C}$ after addition of $200 \mu M$ isopropyl- $\beta$-D-thiogalactoside. Homogenates from cell lysates were applied onto a Ni-Chelating Sepharose Fast Flow column (GE Healthcare). Fractions eluted with $250 \mathrm{mM}$ imidazole were further loaded on a HiPrep 26/10 desalting column (GE Healthcare) that was pre-equilibrated with $50 \mathrm{mM}$ Tris-HCl, pH7.6, $150 \mathrm{mM} \mathrm{NaCl}$, and $1 \mathrm{mM}$ EDTA. The flow-through was concentrated, and aliquots were stored at $-80^{\circ} \mathrm{C}$. Recombinant mature full-length human Ero1 $\alpha$ and PDI proteins were purified as previously described (34).

The cDNA encoding the signal sequence of GPx7 or PDI was added by overlapping PCR using pKEHS780 or pQE30PDI (34) as a template, and then inserted into pcDNA3.1 vector at $\mathrm{XbaI}$ and $\mathrm{KpnI}$ sites to generate plasmids suitable for expression in eukaryotic cells. Mutagenesis was carried out using the Fast Mutagenesis Kit (TransGen) according to the manufacturer's instructions. The pcDNA3.1-Ero1 $\alpha$ construct was used as previously described (21), and pcDNA3.1-Ero1 $\alpha$ with a C-terminal HA tag was constructed by PCR. Each construct was verified by DNA sequencing.

\section{Cell culture, transfection, and antibodies}

HeLa cells were maintained in Dulbecco's modified Eagle's medium (DMEM; Gibco) supplemented with 5\% fetal bovine 
serum (Gibco), 100 units $/ \mathrm{ml}$ penicillin, and $100 \mu \mathrm{g} / \mathrm{ml}$ streptomycin (Gibco) at 5\% CO $\mathrm{CO}_{2}$. HeLa cells were transfected using Lipofectamine2000 (Invitrogen) according to the manufacturer's instructions.

Antibodies to GPx7 were obtained from rabbits on immunization with purified GPx7 protein as an adjuvant. Mouse monoclonal anti-Ero1 $\alpha$ (2G4) and anti-myc (9E10) were used as described (24), while anti-PDI (RL90) and anti-GAPDH (6C5) were purchased from Abcam and Beyotime, respectively.

\section{RNA interference}

For transient knockdown of Ero1 $\alpha$, pSUPER-retro-puro retrovirus vector (Oligoengine) expressing shRNA targeting Ero $1 \alpha$ sequence 5'-GGGACACAACATTACAGAATTTCAA$3^{\prime}$ (10) was constructed following the manufacturer's instructions. The resulting shEro1 $\alpha$ plasmid was transfected into HeLa cells combined with JcM plasmid on day 1 , followed by a second-round transfection of shEro1 $\alpha$ plasmid with GPx7 plasmid on day 3 and subsequent analysis on day 5 .

\section{Enzyme activity assays}

Denatured and reduced RNase A was prepared as described (19). For oxygen consumption assays, all components except Ero1 $\alpha$ were mixed and added to an Oxygraph Clark-type electrode (Hansatech Instruments), followed by an injection of Ero1 $\alpha$ to initiate the reaction. For $\mathrm{H}_{2} \mathrm{O}_{2}$ determination, catalase at $20 \mu \mathrm{g} / \mathrm{ml}$ was injected into the reaction vessel when the thiol oxidation reaction was complete.

RNase A reactivation was assayed by monitoring the $296 \mathrm{~nm}$ absorbance increase at $25^{\circ} \mathrm{C}$ due to the hydrolysis of cCMP as described (34).

GPx activity was measured using a coupled assay after the decrease in absorbance at $340 \mathrm{~nm}$ due to reduced nicotinamide adenine dinucleotide phosphate (NADPH) (0.15 mM; Roche) consumption by glutathione reductase (0.24 unit; Sigma) (22), with addition of $\mathrm{H}_{2} \mathrm{O}_{2}$ or Ero1 $\alpha$ to start the reaction. A molar extinction coefficient of $6200 \mathrm{M}^{-1} \cdot \mathrm{cm}^{-1}$ for NADPH was used for calculations. All experiments were performed in $100 \mathrm{mM}$ Tris-HAc (pH 8.0) containing $50 \mathrm{mM} \mathrm{NaCl}$ and $1 \mathrm{mM}$ EDTA.

\section{Stopped-flow fluorescence}

The oxidation rate of the active site of GPx7 was determined by the decrease of tryptophan fluorescence using a PiStar-180 stopped-flow fluorometer (Applied Photophysics) with an excitation at $280 \mathrm{~nm}$ and a band-pass emission $>320 \mathrm{~nm}$ at $25^{\circ} \mathrm{C}$. The reaction was started by an injection of $0-10 \mathrm{mM} \mathrm{H} \mathrm{H}_{2}$ into $10 \mu M$ GPx7 in $100 \mathrm{mM}$ citrate ( $\mathrm{pH} 7.0$ ), $200 \mathrm{mM} \mathrm{Na} \mathrm{HPO}_{4}$, and $1 \mathrm{mM}$ EDTA.

\section{In vivo oxidative folding assays}

HeLa transfectants expressing JcM were incubated for $5 \mathrm{~min}$ at $37^{\circ} \mathrm{C}$ with $5 \mathrm{mM}$ DTT in DMEM, washed twice with ice-cold phosphate-buffered saline (PBS), and cultured in DMEM without DTT at an indicated temperature (5). Aliquots were taken at different times, quenched with $20 \mathrm{mM}$ N-ethylmaleimide (NEM), lysed in radio immunoprecipitation assay buffer (Beyotime) with NEM and protease inhibitors, and resolved by nonreducing sodium dodecyl sulfate-polyacrylamide gel electrophoresis (SDS-PAGE). Western blots (WB) were developed by anti-myc and enhanced chemiluminescence (ECL) (Thermo
Scientific), followed by using a ChemiScope mini chemiluminescence imaging system (Clinx Science). Band intensities were quantified by densitometry using ImageJ software.

\section{In vitro redox-state measurements, mixed disulfides trapping, and sulfenic acid detection}

To measure the redox states of GPx7, $20 \mu \mathrm{M}$ recombinant GPx7 proteins were incubated with or without $40 \mu \mathrm{M} \mathrm{H}_{2} \mathrm{O}_{2}$ for $15 \mathrm{~min}$. Free thiols were then blocked by adding $2 \mathrm{mM}$ AMS (Invitrogen). For PDI oxidation assays, reactions were initiated by adding $20 \mu \mathrm{M} \mathrm{H}_{2} \mathrm{O}_{2}$ to $20 \mu \mathrm{M}$ GPx7 and $20 \mu \mathrm{M}$ reduced PDI $a$ domain, and samples were taken for quenching using $2 \mathrm{mM}$ AMS at the indicated times. To trap the disulfidelinked complex between GPx7 and PDI, $20 \mu M$ GPx7 and $10 \mu M$ PDI C56A proteins were mixed for $15 \mathrm{~min}$ and then blocked by $20 \mathrm{mM}$ NEM. Samples were then analyzed by SDS-PAGE and Coomassie staining. For sulfenic acid detection, $50 \mu M$ GPx7 proteins were incubated with $100 \mu M \mathrm{H}_{2} \mathrm{O}_{2}$ and $1 \mathrm{mM}$ DCP-Bio1 (KeraFAST) for $30 \mathrm{~min}$. Excess DCP-Bio1 was removed by using Amicon Ultra centrifugal filters (Millipore). Samples were then analyzed by SDS-PAGE, developed by either Coomassie staining or WB using horseradish peroxidise-labeled streptavidin (Beyotime) and ECL. All experiments were performed at $25^{\circ} \mathrm{C}$ in PBS buffer.

\section{Pulldown assays and trapping mixed disulfides in vivo}

For pulldown assay, Glutathione Sepharose resins (GE Healthcare) were incubated with $10 \mu M$ GST-GPx7 fusion proteins and HeLa lysates $(0.5 \mathrm{mg}$ protein $/ \mathrm{ml})$ for $4 \mathrm{~h}$ at $4^{\circ} \mathrm{C}$ in PBS, and washed five times with ice-cold PBS. Bound proteins were detected by Ponceau staining and WB, respectively.

To trap mixed disulfides in vivo, HeLa transfectants were incubated for $10 \mathrm{~min}$ at $37^{\circ} \mathrm{C}$ with or without $5 \mathrm{mM}$ DTT in DMEM, quenched with $40 \mathrm{mM}$ NEM immediately or after DTT washout followed by incubation in DTT-free medium for $30 \mathrm{~min}$. Samples were lysed and analyzed by nonreducing or reducing SDS-PAGE and WB.

\section{Acknowledgments}

The authors thank Lloyd Ruddock for the kind gift of pKEHS780 plasmid, Jiangyun Wang for generously providing a cell culture room, $\mathrm{Si} \mathrm{Wu}$ for technical assistance in stoppedflow determination, and Xi Wang, Xi'e Wang, and Claudio Fagioli for invaluable help. This work was supported by grants from the Chinese Ministry of Science and Technology (2011CB910303 and 2012CB911002) to C.C.W., the National Natural Science Foundation of China (31000351 and 31370775) to L.W., and Telethon (GGP11077) and Associazione Italiana Ricerca Cancro (AIRC; IG and $5 \times 1000$ program) to R.S.

\section{Author Disclosure Statement}

The authors declare that they have no conflicts of interest.

\section{References}

1. Appenzeller-Herzog C, Riemer J, Christensen B, Sorensen ES, and Ellgaard L. A novel disulphide switch mechanism in Ero1 alpha balances ER oxidation in human cells. EMBO J 27: 2977-2987, 2008.

2. Araki K and Inaba K. Structure, mechanism, and evolution of Ero1 family enzymes. Antioxid Redox Signal 16: 790-799, 2012. 
3. Baker KM, Chakravarthi S, Langton KP, Sheppard AM, Lu $\mathrm{H}$, and Bulleid NJ. Low reduction potential of Ero1 alpha regulatory disulphides ensures tight control of substrate oxidation. EMBO J 27: 2988-2997, 2008.

4. Battle D, Gunasekara SD, Watson G, Ahmed EM, Saysell C, Altaf N, Sanusi A, Munipalle P, Scoones D, Walker J, Viswanath $Y$, and Benham A. Expression of the endoplasmic reticulum oxidoreductase Erol $\alpha$ in gastro-intestinal cancer reveals a link between homocysteine and oxidative protein folding. Antioxid Redox Signal 19: 24-35, 2013.

5. Bertoli G, Simmen T, Anelli T, Molteni SN, Fesce R, and Sitia R. Two conserved cysteine triads in human Erolalpha cooperate for efficient disulfide bondformation in the endoplasmic reticulum. J Biol Chem 279: 30047-30052, 2004.

6. Bosello-Travain V, Conrad M, Cozza G, Negro A, Quartesan S, Rossetto M, Roveri A, Toppo S, Ursini F, Zaccarin M, and Maiorino M. Protein disulfide isomerase and glutathione are alternative substrates in the one Cys catalytic cycle of glutathione peroxidase 7. Biochim Biophys Acta 1830: 3846-3857, 2013.

7. Brigelius-Flohé R and Maiorino M. Glutathione peroxidases. Biochim Biophys Acta 1830: 3289-3303, 2013.

8. Bulleid NJ and Ellgaard L. Multiple ways to make disulfides. Trends Biochem Sci 36: 485-492, 2011.

9. Delaunay A, Pflieger D, Barrault MB, Vinh J, and Toledano MB. A thiol peroxidase is an $\mathrm{H}_{2} \mathrm{O}_{2}$ receptor and redoxtransducer in gene activation. Cell 111: 471-481, 2002.

10. Enyedi B, Varnai P, and Geiszt M. Redox state of the endoplasmic reticulum is controlled by Ero1L-alpha and ntraluminal calcium. Antioxid Redox Signal 13: 721-729, 2010.

11. Gross E, Sevier CS, Heldman N, Vitu E, Bentzur M, Kaiser CA, Thorpe C, and Fass D. Generating disulfides enzymatically: reaction products and electron acceptors of the endoplasmic reticulum thiol oxidase Ero1p. Proc Natl Acad Sci U S A 103: 299-304, 2006.

12. Hatahet $\mathrm{F}$ and Ruddock LW. Protein disulfide isomerase: a critical evaluation of its function in disulfide bond formation. Antioxid Redox Signal 11: 2807-2850, 2009.

13. Inaba K, Masui S, lida H, Vavassori S, Sitia R, and Suzuki M. Crystal structures of human Ero1 $\alpha$ reveal the mechanisms of regulated and targeted oxidation of PDI. EMBO J 29: 3330-3343, 2010.

14. Iuchi Y, Okada F, Tsunoda S, Kibe N, Shirasawa N, Ikawa M, Okabe M, Ikeda Y, and Fujii J. Peroxiredoxin 4 knockout results in elevated spermatogenic cell death via oxidative stress. Biochem J 419: 149-158, 2009.

15. Jessop CE, Watkins RH, Simmons JJ, Tasab M, and Bulleid NJ. Protein disulphide isomerase family members show distinct substrate specificity: P5 is targeted to BiP client proteins. J Cell Sci 122: 4287-4295, 2009.

16. Kakihana T, Nagata K, and Sitia R. Peroxides and peroxidases in the endoplasmic reticulum: integrating redox homeostasis and oxidative folding. Antioxid Redox Signal 16: 763-771, 2012.

17. Karala AR, Lappi AK, Saaranen MJ, and Ruddock LW. Efficient peroxide-mediated oxidative refolding of a protein at physiological $\mathrm{pH}$ and implications for oxidative folding in the endoplasmic reticulum. Antioxid Redox Signal 11: 963-970, 2009.

18. Klomsiri C, Nelson KJ, Bechtold E, Soito L, Johnson LC, Lowther WT, Ryu SE, King SB, Furdui CM, and Poole LB. Use of dimedone-based chemical probes for sulfenic acid detection: evaluation of conditions affecting probe incorporation into redox-sensitive proteins. Method Enzymol 473: 77-94, 2010.

19. Lyles MM and Gilbert HF. Catalysis of the oxidative folding of ribonuclease A by protein disulfide isomerase: dependence of the rate on the composition of the redox buffer. Biochemistry 30: 613-619, 1991.
20. Margittai E, Loew P, Stiller I, Greco A, Garcia-Manteiga JM, Pengo N, Benedetti A, Sitia R, and Banhegyi G. Production of $\mathrm{H}_{2} \mathrm{O}_{2}$ in the endoplasmic reticulum promotes in vivo disulfide bond formation. Antioxid Redox Signal 16: 1088-1099, 2012.

21. Mezghrani A, Fassio A, Benham A, Simmen T, Braakman I, and Sitia R. Manipulation of oxidative protein folding and PDI redox state in mammalian cells. EMBO J 20: 6288-6296, 2001.

22. Nguyen VD, Saaranen MJ, Karala AR, Lappi AK, Wang L, Raykhel IB, Alanen HI, Salo KEH, Wang CC, and Ruddock LW. Two endoplasmic reticulum PDI peroxidases increase the efficiency of the use of peroxide during disulfide bond formation. J Mol Biol 406: 503-515, 2011.

23. Peng DF, Belkhiri A, Hu TL, Chaturvedi R, Asim M, Wilson KT, Zaika A, and El-Rifai W. Glutathione peroxidase 7 protects against oxidative DNA damage in oesophageal cells. Gut 61: 1250-1260, 2012.

24. Ronzoni R, Anelli T, Brunati M, Cortini M, Fagioli C, and Sitia R. Pathogenesis of ER storage disorders: modulating russell body biogenesis by altering proximal and distal quality control. Traffic 11: 947-957, 2010.

25. Schulman S, Wang B, Li WK, and Rapoport TA. Vitamin K epoxide reductase prefers ER membrane-anchored thioredoxin-like redox partners. Proc Natl Acad Sci U S A 107: 15027-15032, 2010.

26. Sevier CS and Kaiser CA. Ero1 and redox homeostasis in the endoplasmic reticulum. Biochim Biophys Acta 1783:549-556, 2008.

27. Sevier CS, Qu HJ, Heldman N, Gross E, Fass D, and Kaiser CA. Modulation of cellular disulfide-bond formation and the ER redox environment by feedback-regulation of Ero1. Cell 129: 333-344, 2007.

28. Tavender TJ, Springate JJ, and Bulleid NJ. Recycling of peroxiredoxin IV provides a novel pathway for disulphide formation in the endoplasmic reticulum. EMBO J 29: 4185-4197, 2010.

29. Toppo S, Vanin S, Bosello V, and Tosatto SCE. Evolutionary and structural insights into the multifaceted glutathione peroxidase (Gpx) superfamily. Antioxid Redox Signal 10: 1501-1513, 2008.

30. Utomo A, Jiang XZ, Furuta S, Yun J, Levin DS, Wang YCJ, Desai KV, Green JE, Chen PL, and Lee WH. Identification of a novel putative non-selenocysteine containing phospholipid hydroperoxide glutathione peroxidase (NPGPx) essential for alleviating oxidative stress generated from polyunsaturated fatty acids in breast cancer cells. J Biol Chem 279: 43522-43529, 2004.

31. van Lith M, Tiwari S, Pediani J, Milligan G, and Bulleid NJ. Real-time monitoring of redox changes in the mammalian endoplasmic reticulum. J Cell Sci 124: 2349-2356, 2011.

32. Wang C, Li W, Ren J, Fang J, Ke H, Gong W, Feng W, and Wang CC. Structural insights into the redox-regulated dynamic conformations of human protein disulfide isomerase. Antioxid Redox Signal 19: 36-45, 2013.

33. Wang C, Yu J, Huo L, Wang L, Feng W, and Wang CC. Human protein-disulfide isomerase is a redox-regulated chaperone activated by oxidation of domain a'. J Biol Chem 287: 1139-1149, 2012.

34. Wang L, Li SJ, Sidhu A, Zhu L, Liang Y, Freedman RB, and Wang CC. Reconstitution of human Ero1-Lalpha/protein-disulfide isomerase oxidative folding pathway in vitro. Positiondependent differences in role between the a and a' domains of protein-disulfide isomerase. J Biol Chem 284: 199-206, 2009.

35. Wang L, Zhu L, and Wang CC. The endoplasmic reticulum sulfhydryl oxidase Ero1 beta drives efficient oxidative protein folding with loose regulation. Biochem J 434: 113-121, 2011. 
36. Wang X, Wang L, Wang Xe, Sun F, and Wang CC. Structural insights into the peroxidase activity and inactivation of human peroxiredoxin 4. Biochem J 441: 113-118, 2012.

37. Wei P-C, Hsieh Y-H, Su M-I, Jiang X, Hsu P-H, Lo W-T, Weng J-Y, Jeng $Y-M$, Wang J-M, Chen P-l, Chang $Y-C$, Lee $\mathrm{K}-\mathrm{F}$, Tsai M-D, Shew J-Y, and Lee W-H. Loss of the oxidative stress sensor NPGPx compromises GRP78 chaperone activity and induces systemic disease. Mol Cell 48: 747-759, 2012.

38. Zito E, Hansen HG, Yeo GSH, Fujii J, and Ron D. Endoplasmic reticulum thiol oxidase deficiency leads to ascorbic acid depletion and noncanonical scurvy in mice. Mol Cell 48: 39-51, 2012.

39. Zito E, Melo EP, Yang Y, Wahlander A, Neubert TA, and Ron D. Oxidative protein folding by an endoplasmic reticulum-localized peroxiredoxin. Mol Cell 40: 787-797, 2010.

Address correspondence to: Dr. Lei Wang

National Laboratory of Biomacromolecules Institute of Biophysics Chinese Academy of Sciences Beijing 100101

China

E-mail: wanglei@moon.ibp.ac.cn

Prof. Chih-chen Wang National Laboratory of Biomacromolecules Institute of Biophysics Chinese Academy of Sciences Beijing 100101

China

E-mail: chiwang@sun5.ibp.ac.cn
Date of first submission to ARS Central, February 8, 2013; date of final revised submission, July 18, 2013; date of acceptance, August 6, 2013.

\begin{tabular}{|c|}
\hline Abbreviations Used \\
\hline $\begin{array}{c}\text { AMS }=4 \text {-acetamido- } 4 \text { '-maleimidylstilbene-2, } 2^{\prime}- \\
\text { disulfonic acid }\end{array}$ \\
\hline$C_{P}=$ peroxidatic cysteine \\
\hline$C_{R}=$ resolving cysteine \\
\hline DCP-Bio1 = 3-(2,4-dioxocyclohexyl) propyl with a \\
\hline biotin tag \\
\hline DMEM $=$ Dulbecco's modified Eagle's medium \\
\hline $\mathrm{DTT}=$ dithiothreitol \\
\hline $\mathrm{ECL}=$ enhanced chemiluminescence \\
\hline $\mathrm{ER}=$ endoplasmic reticulum \\
\hline GPx7 $=$ glutathione peroxidase 7 \\
\hline $\mathrm{GSH}=$ reduced glutathione \\
\hline GSSG $=$ oxidized glutathione \\
\hline $\mathrm{GST}=$ glutathione S-transferase \\
\hline $\mathrm{JcM}=$ myc-tagged Ig-J chains \\
\hline $\begin{array}{l}\mathrm{NADPH}=\text { reduced nicotinamide adenine dinucleotide } \\
\text { phosphate }\end{array}$ \\
\hline NEM $=$ N-ethylmaleimide \\
\hline $\mathrm{PBS}=$ phosphate-buffered saline \\
\hline PDI $=$ protein disulfide isomerase \\
\hline $\operatorname{Pr} \times 4=$ peroxiredoxin 4 \\
\hline $\begin{array}{c}\text { SDS-PAGE }=\begin{array}{c}\text { sodium dodecyl sulfate-polyacrylamide gel } \\
\text { electrophoresis }\end{array}\end{array}$ \\
\hline $\mathrm{WB}=\mathrm{Western}$ blots \\
\hline WT $=$ wild-type \\
\hline
\end{tabular}

